\title{
Reactions to "1985 to 1995: The Next Decade in Academic Librarianship,' ' Parts I and II
}

\author{
Jane B. Robbins-Carter, Johannah Sherrer, \\ Deborah Jakubs, and Charles B. Lowry
}

\section{REACTION FROM JANE B. ROBBINS-CARTER}

Veaner, rightly, I believe, begins his paper with a "cautions" section and reminds readers, "Modern life is a perpetual ferment of paradox and contradiction" (p.4). He further reminds us that though most prophecies end up somewhat off the mark, it is often possible to forward reasonable approximations of short-term futures. I commend Veaner's broad-ranging paper for the many facets of today's roiling academic and technological environment that he attempts to settle as he relates them to changes in academic librarianship in the decade ahead. I believe he forecasts a probable and desirable future. His analysis deserves broad distribution and reasoned response. As but one reader, I have found very much in his paper about which to comment; however, I will limit my response to but two areas that he has addressed. The first is that of new or alternative administrative structures for academic library management, and the second is education for academic librarianship.

\section{Governance in Academic Libraries}

Veaner correctly points out that many management scholars, consultants, and practitioners believe that changes in the social and technological fabric of society, i.e., the developing information society, are signaling, if not requiring, that bureaucratic functional/hierarchical governance structures must be redesigned. Required are organizational structures that begin with a focus on outputs to be consumed (or even more challenging outcomes to be realized) through use of the library. Such a refocusing calls for academic librarians to boldly redesign the structures of our libraries. Many of us have blanched at criticisms laid by faculty advisory groups and public policy analysts, which inform us that from their perspectives it appears that libraries are structured principly for the convenience of librarians rather than users. (We blanch from these criticisms because we know that for the most part they contain an operative nucleus of accuracy.)

Our current functional structures organized around acquisition, cataloging, circulation, and reference, often overlaid with a form of material departmentalization, emphasize control of material over material use. We almost always argue that we must emphasize control because of future potential uses by others; we rarely place our priorities on service to those presently requiring the material. Public

Jane B. Robbins-Carter is a professor and director of the School of Library and Information Studies at the University of Wisconsin-Madison, Madison, Wisconsin 53706. Johannah Sherrer is director of public services in the Michener Library at the University of Northern Colorado, Greeley, Colorado 80639. Deborah Jakubs is general bibliographer in the William R. Perkins Library at Duke University, Durham, North Carolina 27706. Charles B. Lowry is director of libraries at the University of South Alabama, Mobile, Alabama 36688. He was recently appointed director of libraries at the University of Texas at Arlington, a post he will assume on July 1, 1985. 
administration analysts would, I believe, argue that we have suboptimized the bibliographic control function to the detriment of the purpose of our librariesinformation provision. Devising truly new organizational structures is not an easy task; however, if Veaner is right, as I fervently hope he is, that the production responsibilities in libraries will continue to be shifted to support personnel, we may somewhat more easily be released from our present organizational structures because professional librarians will no longer be doing the production work around which our libraries are focused. As Abell calls for, we should restructure our academic libraries to emphasize services related to disciplinary groupings. These groupings form the very basis of the organization of the academic environment in which the library is embedded. While academic librarians have claimed that they are closely allied with the faculty in the teaching and research mission of academe, our organizational structures have belied that alliance. We have structured our libraries more akin to the physical plant maintenance activities of universities than to teaching and research activities. The academic library structured around services to disciplines rather than around library functions would encourage the entrepreneurial attitudes claimed by Veaner to be important in the changing academic environment.

While Veaner states that "the governance issue ... is far, far behind the role issue for librarians," I would argue that new structures may greatly facilitate, and in fact may be essential to accomplish role change for librarians. It will be extremely difficult, if not impossible, to foster productive competition and entreprenurial attitudes if we maintain our present functional structures. Interaction with departmental faculty can be fostered by disciplinary-focused academic librarians in the area of bibliographic instruction. Such instruction should be offered through academic departments, which in my view is the only means by which truly meaningful bibliographic instruction can be accomplished. Librarians allied with disciplines may also interact with faculty more readily through participation in the research process of individual faculty or faculty groups. Such interaction is presently militated against by our libraries' function-focused structures. Bold new disciplinary service organizational structures are required. It is ironic that the radical change in organizational structure that is required can be facilitated by the hierarchical bureaucracy that now permeates our libraries. What is required is the willingness of some few academic librarians to skillfully impose the needed organizational change. (This enforcement of an organizational structure, which requires team approaches to service-focused librarianship, is simply an illustration of the paradox and contradiction that Veaner claims permeates our times.)

\section{Education for Academic Librarianship}

I wish to begin this section of my response with a hearty endorsement of one of Veaner's recommendations in the area of graduate education. It calls for more open communication between teaching faculty and librarians. Veaner recommends that academic librarians work with ALISE (Association for Library and Information Science Education) and funding organizations to establish a systematic program of linking faculty and curricula to the working realities in the modern academic library. Such linkage has been addressed by ALISE through a policy statement and through an ACRL committee, but it needs to be pursued more aggressively. While I certainly understand the tension (some of which is very healthy for the profession) that arises between educators and practitioners, I believe we need to share with each other our knowledge and vision. Our dialogues need to be more clearly centered on sharing legitimate perspectives rather than casting blame for faults that are observed. Many of us are deeply committed to librarianship as a profession and I believe that with the aid of practitioners through guest lecturing, research activities, professional committee service, and a variety of other joint ac- 
tivities we can make education for librarianship truly contributive to the goal of changing the practice of academic and research librarianship.

Many educators responsible for academic and research librarianship work diligently to remain abreast of the changes affecting the field. Due to the nature of the teaching profession, they are able to read extensively; further, they come into contact with a wide variety of support staff, from many different libraries, who have chosen to attend library school. They hear about the array of practices in the field as applied from the smallest academic libraries to the largest. They are, as are their practicing colleagues, frustrated by the cacophony of aspects impinging on the field and are very concerned about what is most important to teach to future professionals. The observed trend in curricular design is very much away from technique and production toward the conceptual and management concerns.

Many students come to our schools hoping to "hear the word" from the professoriat. They too become frustrated when they find that we teach for just those types of qualities that Veaner, Battin, and others call for, i.e., multiple working styles, flexibility and adaptability, knowledge of higher education, and even entrepreneurial attitudes. Some faculty plant seeds in students' minds that they might even practice academic librarianship from an academic departmental home rather than from a home in a library. (Such suggestions are embraced by very few; most of our students consider the "deinstitutionalization" of instruction, i.e., a focus on the provision of information services regardless of from where these services emerge, as rather a betrayal.) As Veaner contends, in periods of rapid change when even the short-range future is so uncertain, there is a tendency to entrench traditional views.

Despite very serious concerns related to the education of professional librarians, I believe that the most serious problem facing the field is not the education of professionals, because many changes have taken place, but rather the education of support staff. Throughout his paper, Veaner again and again speaks of the changing nature of the work force in academic libraries:

The broad and general removal of production/ manufacturing work from academic librarians is the most important change and the most valuable opportunity now before the ACRL community.

A major thrust of this paper is the contention that academic librarians' responsibilities have shifted heavily from production to management.

As technical work in library and information is increasingly offloaded to support staff.

We seem to have returned in a significant way to the pre-twentieth-century condition when virtually all of the education for the skill level of librarianship takes place within our libraries. Surely, if professionals are no longer doing what they used to do but that related, now nonprofessional work still must be done, the professionals must be training the staff. Faculty have heard that today's academic librarians need knowledge of teaching techniques and adult learning theory in order to better design and deliver bibliographic instruction; however, little is said about these same skills in relation to the training of support staff.

ALA's "Library Education and Personnel Utilization" (LEPU) statement addresses support personnel including library associates, library technical assistants, and clerks. The category of support personnel to which growing and important work is being shifted is the library associate category. The educational requirement for this category is the "bachelor's degree (with or without course work in library science); or bachelor's degree plus additional academic work short of the master's degree." Most of our accredited educational programs are not designed to be consumed "in part" by those who do not intend to become professionals. If, indeed, our programs at the M.A. level have changed as is called for, very few of the courses should be relevant to support staff. While I have little doubt that the professional staff of academic libraries 
are capable of training support staff, I fear that the time that they should be spending on interaction with faculty and students, i.e., the delivery of service, will be absorbed by the necessity to train support staff, once again turning our energies to the production function of the library, not its service function.

I believe the time has come to address seriously the question of the needed education of library support staff. Many professional fields have developed educational programs for support staff, e.g., dental hygienists, paralegals, physicians' assistants, and nurse practitioners. ALA's Office for Library Personnel Resources is presently conducting a review of the LEPU statement. I trust that my concern is shared with a sufficient number of others and that educational programs for support staff will soon become a reality.

It has been said that the salutation "May you live in interesting times" is really a curse. We do live in most interesting times for librarians. Let us embrace them, take some risks, design more new organizational structures and instructional programs, and then evaluate what happens! If we do not do so aggressively, we have much to lose.

\section{REACTION FROM JOHANNAH SHERRER}

\section{Veaner's View of the Future}

Veaner's study presents provocative scenarios for academic librarianship over the course of the next ten years. His projections are low-key and somewhat conservative. The conservative tone is set by Veaner's balanced rational approach that in itself rejects wild futuristic projections. Because of this it is difficult to disagree in any significant measure with the overall content of this exploratory, broadly based composition.

Criticism could be leveled, however, at what was not examined in the study. One item absent was a reference to declining college enrollments and the effects this factor may have on the economic future of academic libraries. All change has finan- cial implications. In libraries, the degree to which new technologies are incorporated will almost always have a relationship to the amount of available funding. The study of financial structures governing academic institutions and their libraries would be an appropriate activity in the upcoming decade. These structures vary in detail from institution to institution, and failing to address the problem at a local level will effect the thoughtful advancement of individual academic environments.

In addressing personnel issues in academic librarianship, especially those of derecruitment or outplacement, Veaner's perspective is not that of the "working librarian." Furthermore, he fails to address a growing problem throughout all of academia, specifically the declining mobility of its professional staff. The next ten years will continue to witness the lack of mobility among academic employees. Moreover, trends toward rigid tenure requirements may dissuade many from moving even when economic factors do not prohibit such attempts. Long-term employees may well be a phenomenon on the increase unless there is a significant change in economic factors such as interest rates and regular cost-of-living enhancements. Emphasis on hiring only superbly qualified individuals will not be a sufficient solution to this problem unless there is managerial talent prepared to create and monitor an environment that encourages professional growth.

Veaner states that "every institution has a social obligation to long-term employees." He goes on to imply that the principle challenge of this obligation is a financial one in terms of encouraging early retirement or other "buy out" plans. Most "working librarians" would probably disagree and assert that the principle challenge is in locating talented, creative administrators who recognize that obligations to long-term employees include creating a challenging and satisfying work environment where daily problems are confronted directly. At any rate, ineffectual managers, however skilled they may be in campus politics and public relations, must be prepared to acknowledge 
responsibility for creative, positive management maneuvers that enhance productivity rather than stymie it.

Veaner's emphasis on derecruitment of "deadwood" presents a rather flippant analogy to weeding personnel as one would weed books. Veaner states that the profession has no mechanism in place for derecruitment or outplacement and further suggests that it would be difficult, perhaps impossible, for ACRL to enter into this area. Mechanisms, however, do exist for this problem but, as in other areas of academe, they are rarely employed. The mechanisms are routine evaluation procedures, and ACRL could be of enormous assistance by providing written guidelines that define levels of performance in academic librarianship.

\section{Successes and Difficulties \\ in Academic Librarianship}

The key to success in librarianship rests in the ability to be flexible, objective, and comfortable in continually reassessing decisions and professional commitments. These components will permit the widest possible margin of success. Veaner's view that academic librarians have embraced innovations far more rapidly than other members of academe is an accurate one. The real challenge lies in persuading academic administrators that the viability of their libraries is dependent on change and the wise incorporation of appropriate technological innovations. While university administrations strive to endorse funding for research and development, endorsing the same concept in the development of library services has not been eagerly embraced. Because of these factors, only a few institutions will progress successfully to the fullest extent possible during the next ten years. Yet, as we have seen in the previous ten years, the practical assimilation of computerized bibliographical utilities and products will progress steadily in all academic libraries. Examples of additional successes will be continued efforts at networking, technology adaptation, and increasingly effective marketing of library services. Failures in academic librarianship will continue in the same areas that have always been weak or ambiguous. The areas of faculty status, the role of the academic librarian, and personnel management may well go unresolved.

In summary, Veaner suggests that achievements in academic librarianship will continue to occur in those areas that have a history of success. He is less sanguine about areas that are currently weak or ambiguous. In fact, his reluctance to postulate a resolution on issues such as faculty status and role clarification is an acknowledgment not only of the difficulties inherent in the issues themselves, but also an acknowledgement of concern as to the probability of ACRL successfully grappling with these significant problem issues in the near future. How truly significant it would be if academic librarianship could gain measurable strides in just one of these weak or ambiguous areas. To succeed in areas of strength is usually far less significant than succeeding in areas of known weaknesses.

\section{The Knowledge Role}

The "knowledge role" has always existed among academic librarians. It has been most visible among librarians engaged in reference services and collection development activities. It has gained recent status in the professional literature primarily due to the decrease of professional involvement in technical service activity. Is the "knowledge" role more important in the upcoming decade than in past decades? I think not. It has always been acutely important, but its function is perhaps now more noticeable and professionally attractive to promote.

\section{Current Functions and Future Requirements}

Academic librarians will adjust easily and eagerly to the new skills and requirements needed for the successful implementation of improved library services. The structure for such an occurrence is already in place. We have a body of literature that can be expanded, tightened, enhanced, or revised as we wish. The key issue is that a body of literature does exist and its writings do project an image and to 
a great degree reveal our own perception of our role.

Our professional association is a vocal one and one that endeavors to appeal to the working librarian. With this orientation it has the ability to garner strong grass-roots support and represent a wide, all-encompassing base.

ACRL's strong stand on quality continuing education provides a mechanism for professionals to acquire needed skills or information pertaining to new trends in the field. This emphasis also serves as a constant reminder that we each have a professional obligation to continually enhance our own professional growth and development.

We have a body of literature, a strong professional association, an acknowledged dependence on quality continuing education, and a belief that collegial communication through meetings, workshops, and informal get togethers can foster continued growth and development. We will be held in check primarily by the cumbersome, broader organizational framework that generally characterizes academic institutions of higher education. This check should serve also as our challenge. The ability to persuade our academic colleagues that they need access to creative library services will help. Our ability to justify this role will depend entirely on those of us working directly with the library users. We need to present the working librarian as a broadly educated, well-read, articulate professional with sound communication abilities.

\section{REACTION FROM DEBORAH JAKUBS}

Librarians are facing a crisis and a challenge in the decade ahead. Changes in our environment are forcing us to do what $\mathrm{Al}$ len Veaner has done: to look long and hard at our goals and our roles in order to seize the opportunities that technology and changes in patterns of scholarship and the organization of knowledge are offering. It is a critical time to aim to improve our image and status as individuals and as a group. We are faced with an opportunity to innovate, to add layers of complexity to our tasks, as well as to reaffirm our traditional role, thus renewing the spirit of the profession.

Allen Veaner's article provides much food for thought. I agree generally with his view of the future for librarians, but I would like to stress that most of his conclusions are predicated on a few very basic changes that must come about before we are able to accept the new responsibilities he foresees for the coming decade. I will focus my comments on those fundamental changes. The first and most important change must take place in the internal and external image of the librarian. We must clarify our identity, as individuals and as a profession, if we are to meet the approaching challenges. If we are to expand our skills as Veaner suggests, we must welcome innovation in both the technological and organizational spheres of our professional lives and call attention to our ability to handle it. This implies that we must, in effect, do more than keep up with change; we should anticipate it and initiate it.

Veaner calls attention to the "fuzzy image" of librarians. I would add that we are often taken for granted within the university, where the primary players are generally perceived to be faculty and students. We are partly at fault for this low visibility. It is significant that we find it necessary to compare ourselves with faculty. It is as if we had no internal model, no professional definition (other than the M.L.S., and that degree is not always a consistent criterion), for what it takes, what it means to be a librarian. I would venture to say that it is a lack of confidence-maybe not always overt, perhaps only nagging, but persistent nonetheless-in our role and worth in the research community that drives us to seek our model in the faculty. We must, in the decade ahead, give ourselves credit, make it clear first to ourselves, then to others, that we like our jobs, we have chosen to be librarians, and we have important skills to share. We do not wish to be compared with faculty (though we may envy their economic benefits and summers off), nor should we be. While our jobs both require serious intellectual effort, they are also very different. As a colleague put it, 
"If we wanted to be faculty, we would be faculty." The fact is that we have chosen to be librarians, and although faculty are our closest models, it does not benefit us to be compared to them or to imagine ourselves to be in their shadow.

Publishing serious scholarly work should continue to be an important factor in evaluating librarians, but again, our situation differs significantly from that of faculty. Most of us hold full-time jobs and are not expected or encouraged to carry out research and writing on "company time," whereas writing is a part of a professor's daily routine. How can we incorporate research and writing officially into our positions? What about allowing sabbaticals for librarians, or making formal acknowledgement of the need to publish? Perhaps we should review the criteria we use to determine the quality of a librarian's performance to determine the importance of publishing as compared with other standards.

Work on changing our self-image should begin in the library schools. I wholeheartedly agree with Veaner that there must be improvement in graduate library education before we will be up to meeting the challenges of the next decade. The library profession should be concerned about attracting bright and dynamic individuals with well-developed interpersonal skills who are seeking a library degree because they are actively attracted to the job of librarian, not merely because they like to read or "enjoy books." Ours should not be perceived as a passive profession. Similarly, the library school curriculum should be revised to reflect the "competencies" Veaner has emphasized, incorporating the rigor necessary to make it a truly professional program of study. We should stress management and analytical skills as well as technological foresight, all of which will be required of successful librarians in the future.

To change our external image successfully will require the education of faculty and administrators. Let's face it: many, if not most faculty members have but a slight grasp of the complexity, bibliographic and otherwise, of library work. Their main concern when it comes to the library is that the librarians have anticipated their research needs, already have ordered the appropriate materials, and have them available on the shelf. This is, of course, a legitimate desire and one that a good collection development librarian should aim to fulfill. But those research needs are rapidly changing and are no longer restricted to books. Librarians have a larger role to play (as Veaner indicates) as intermediaries, teachers, and interpreters. We should turn the needs of our patrons to our advantage and equip ourselves with the knowledge to satisfy their demands. The process of educating faculty must be conducted one-on-one. Few faculty members are interested in attending meetings to learn about the library's functions. They are primarily interested in what can help them specifically, in learning what they need to know to take the next step in their research, to get books ordered for reserves, etc. Our goal then is to accept both the "traditional" and "knowledge" roles (as Veaner describes them) with confidence. It is to understand and anticipate patrons' needs and to display our knowledge and abilities as part of our job. Faculty respond well to librarians they respect and trust to interpret their work, and news travels fast within academic departments. Patrons, especially faculty, can be both our worst detractors and our most loyal and vocal supporters. In the chain of educating the university community about the library and librarians, this kind of direct communication with faculty, whether it involves consulting on the value of adding a periodical title to the collection or discussing the features of a new database, is the strongest link.

One further point on our image: the library and the librarian are more constant than the faculty in the life of the university. It is not true that librarians do not teach useful skills. In many cases, in fact, students learn from librarians skills upon which they will rely throughout their lives (in contrast with some of what they may learn in class). Thus, the librarian can play a critical role in the university and should be encouraged to pursue broader involvement in the institution. This may include participating in university-wide commit- 
tees, not only those with direct relevance for the library. We are in an excellent position to learn daily about the educational process at our respective institutions through formal and informal relationships. We must take the initiative to make worthwhile contributions of our ideas and energy to the university.

Consistent external support is another precondition for the implementation of Veaner's ideas and predictions. If we succeed at educating faculty and administrators, we are opening lines of communication that will facilitate our securing that support. Without that assistance, librarians will have a difficult time adapting to what will be required of them. Librarians have many good ideas; many may already have anticipated Veaner's predictions, at least in their minds or even on paper. But these ideas will not reach fruition and will result only in frustration if the university administration is not sympathetic to them and convinced of the necessity of their implementation. A good example is the closer relationship Veaner envisions between the library and the university computation center. It is almost certain that many of the same questions are debated and discussed across campus in different forums. If it were possible to forge the links Veaner describes and coordinate the efforts of various groups, foremost among them the library, much energy could be redirected and the library would be drawn into university decision making, as it should be,

Just as educating faculty and administrators is not an easy task, Veaner's call to "restructure the academic library" will take time. If it is true that change comes slowly to the university, it comes even more slowly to the library. We have a lot of organizing to do in our workplaces to devise and agree on joint goals and to convince our colleagues throughout the library of the need for restructuring. Overcoming departmentalization will not be easy. Veaner's article might have benefitted from more attention to technical services librarians and what they can expect during the next decade. Except for a few references to catalogers, his "academic librarian" seems to resemble more closely an individual working in public services. Additional discussion of the necessary interaction between technical and public services in meeting the challenges of the future would have clarified the specifics of the challenge he foresees. Shared goals, improved communication, and an open attitude toward change are only a few of the prerequisites for the adaptations Veaner has identified as likely to face us in the coming decade.

In short, we are facing a set of challenges that require that we overcome what might be called an "identity crisis" if we are to meet them. The preconditions for our succeeding are few but critical. Librarians must work to become more confident as individuals and as a profession. We must forge direct, collegial relationships with faculty, administrators, and other patrons, educating them to the problems and potential of the library. At the same time, we must seek tangible support for the technological growth and staff training that will be required. It is not only the library but the university as a whole that will be experiencing change, and librarians have a large and critical role to play in that process. We should begin now to organize ourselves to meet the challenges that Veaner has described.

\section{REACTION FROM CHARLES B. LOWRY}

In the welter of concern about the role of academic librarianship in the "electronic" libraries of the future, Allen Veaner identifies the extreme positions and provides a balanced and insightful analysis of the forces that we face. He rightly rejects what might be called the "Jeremiah position" that librarianship is doomed as a discipline and profession or the "Pollyanna position" that we shall move into the future by just doing the same old things better. He provides a concrete set of actions to be taken by individual academic librarians and in concert through their primary professional organization, the Association of College and Research Libraries (ACRL). This is not some middle-ground compromise but a lucid vision for action. The fact 
remains that this is an important paper that should be read again and again. Moreover, it should be acted upon.

Veaner's paper is divided into two parts and includes a series of recommendations to ACRL. Part I deals with the context, fundamental changes, and possible futures for librarianship and Part II with the knowledge, skills, abilities, and attitudes that will be required of individual librarians over the decade from 1985 to 1995 . One should remember that the context of the paper is the academic library, and that many of its prescriptions are relevant only in that context. Nonetheless, the analysis is frequently applicable to librarians in other types of libraries.

Veaner's premise is that libraries will continue to exist, whatever they are called, and will house both print and electronic formats. But fundamental changes occurring in information technology will dictate a transformation. In some ways the electronic information of the future will be more difficult for the end user to access because of its "invisibility," its technological base requiring systems knowledge, its quality of being reorganizable, and its costliness. Given these conditions, librarians, by whatever name, will be the "expert intermediaries in the research process." They are "capable of complementing faculty through several invaluable roles: research colleague, bibliographic expert, system manager, and information system instructor."

Veaner touches on the need for the librarian to develop links between information systems by working with technologists. There is great opportunity here. For instance, some of the best integrated library automation comes from systems developed in academic libraries. Because technologists who develop information systems rarely have the background to deal with the world of researchers who use those systems, academic librarians must associate themselves as closely as possible with technologists, especially in the computer center, and librarians will perforce continue playing the key role of interpreting those systems to end users who are unlikely to develop the requisite expertise.
The related question of whether new information technologies are available for free is really a straw man issue. Of course they are not, but the issue is whether cost will be directly charged to patrons or budgeted in some other way. A new kind of financial accountability will arise from these circumstances. However, Veaner does not adequately address the conundrum that results when the network or commercial vendor tries to secure its fiscal future through attempts to control information by controlling the "package" it is in. For instance, OCLC's copyright does not apply to the data itself but to the format. ALA has appointed a task force on this issue. ACRL should likewise take concrete action with regard to the uses of copyright.

Librarianship is above all an intellectual enterprise involving people, physical resources, and a communication system. As such it is a discipline unlike others in academe. Given this fact, its role in academe must be articulated and secured. In part this can be accomplished by enhancing the value of the MLS through several measures: strengthening curricula, recruiting the "best and brightest" students, and expanding study to two full years. However, this work will not be successful unless the image, status, and pay of academic librarians is commensurate with their role, and Veaner prescribes steps which we must take to achieve this end. Among these, cooperation with other learned societies is an excellent idea, but changing attitudes at grass roots, especially those of our local faculty, are essential. Likewise, programs to educate academic administrators are essential to combat misperceptions of librarians. The Alliance for Excellence pointed to this need in the K-12 sector. It is equally important in postsecondary education. In higher education, administrators generally are trained in specific subject disciplines and rise through the professorial ranks to administrative positions. It is not surprising then that their view of what a library is or should be is largely determined by the experiences they had in graduate school or as an academic teacher and researcher. The work of broadening this perspective will fall most heavily on 
the chief library administrator. But individual librarians must act in ways that are proactive and demonstrate the value of their role while understanding that library faculty will be distinguished by the very nature of their activities from their teaching colleagues.

The idea that management is supplanting production in librarianship is a key idea in Veaner's analysis and is probably correct. He believes that the application of technology (particularly automation) and standardization in libraries transforms the work of librarians in two ways. The traditional "production" work is "off-loaded" to clerical staff simply because it has become routine. This trend will continue and accelerate, leaving librarians the dual responsibility of managing the use and development of information systems that will require both intellectual and fiscal management skills. Equally important will be the management of staff who are assuming the more routine but technology-based work of libraries. However, the paper is too sanquine in its estimates of the effects this will have on the profession. It will take longer than ten years for library schools to transform curricula and provide the "intellectual" skills and training required and even longer for the job advertisements for library faculty to reflect these requirements instead of "production" skills.

Veaner has prepared eighteen wellconstructed recommendations for ACRL that provide a plan of action designed (1) to assure that the role and status of librarians are clearly understood in the academic community, (2) to provide the "best and brightest" librarians to fulfill that critical role, and (3) to ensure the centrality of librarianship to the teaching and research missions of postsecondary education. Certainly, each of these recommendations can be effective if supported by an appropriate plan of action. However, it will be no easy task for ACRL to secure organizational and fiscal support for this agenda. Veaner has in fact pointed out a serious obstacle. "In many ways ACRL represents the ultimate in professional fragmentation so characteristic of librarianship. The ALA Handbook of Organization for 1983-84 reveals that ACRL is comprised of nearly 250 separately identifiable units."

This commentary has supported Allen Veaner's assessment of our present situation, vision of the future, and recommendations for action. In concluding, the author would suggest several additional but related recommendations for ACRL: (1) Centrifugal forces have been unleashed by the database copyright issue. ACRL should actively participate in this debate and develop a coherent position that does more than merely state the problem. The ACRL position should be aimed at defusing the copyright issue in order to maintain the invaluable resource-sharing system represented by networks. (2) Veaner emphasized the need to diversify and strengthen graduate training in librarianship. ACRL should also find ways to encourage the retraining of librarians in the field. Workshops and symposia are important in this process, but library schools can play a significant role as a resource for retraining. (3) Veaner wishes librarians to increase their research and publication activity. Similarly, he has called for them to involve themselves with technologists in providing innovation in information systems. It is clear that grants are the lifeblood of research and publication in many subject disciplines. Significant resources for research need to be available to librarians as well. ACRL should find ways to provide grant money for original research that will help librarians to develop new information delivery systems and interfaces between those that do exist (whether manual or electronic). (4) Veaner suggests that ACRL should change its name to the Association of College and Research Librarians. This he rightly believes will place the organization in the same stance as the scholarly associations in the subject disciplines. This recommendation arises from the fact that librarians are too often associated with buildings, equipment, and collections rather than librarianship. True though this may be, academic libraries will continue to be the vehicle through which librarianship supports the research and teaching functions. It is important that ACRL support adequate funding of li- 
braries by setting in motion a mechanism for continued revision of the standards for college and junior college libraries. Moreover, these standards should be seriously adopted by higher education in general as benchmarks of library service and should result in funding when they reveal inadequacy. ACRL should also encourage regional accrediting agencies to use such standards or develop standards of their own. We should not underestimate the significance of the effect that standards can have on the debate over resource allocation in our colleges and universities. It is clear that academic administrators take seriously the requirements of accrediting agencies in the subject disciplines, and ACRL standards may do the same for libraries.

\section{IN FORTHCOMING ISSUES OF COLLEGE \& RESEARCH LIBRARIES}

Academic Library Services: The Literature of Innovation

by Judy Reynolds and Jo Bell Whitlach

Circulation Service Desk Operations: Costing and Management Data by Pat Weaver-Meyers, Duncan Aldrich, and Robert B. Seal

Research Libraries in an International Setting: Requirements for Expanded Resource Sharing by Richard M. Dougherty

The State of Public Relations in Academic Libraries by Vikki Ford

Thinking Big: A Commentary on the Research Agenda in Academic Librarianship by Paul Metz 